\title{
The influence of social support and physician recommendation on breast cancer screening practices of immigrant Iranian women in the United States
}

\begin{abstract}
The purpose of this study was to examine the influence of women's reported social support and physician recommnedation on breast cancer screening practices of immigrant Iranian women in the United States.
\end{abstract}

Methods: Logistic regression was used to identify predictors of women's breast cancer screening. The logistic regression results appear as odds ratios (ORs) and 95\% confidence intervals. Backward stepwise multivariate logistic regression using the method of likelihood estimation was conducted to identify the most important predictors after adjusting for other variables $(\mathrm{P}>.05$ for removal from model).

Results: Women who received support from their friends to perform breast self-exams (BSE) were 2.13 times more likely to have ever had a BSE. Women who received support from their husbands/partners were 3.5 times more likely to have ever had a clinical breast exam (CBE) and 2.15 times more likey to get a mamogram.

Conclusion: Findings suggest perceived social support is associated with ever having had BSE and CBE and mamogram. In addition, socioeconomic status, having a usual source of care, and having a physician's recommendation all predict screenin gpractices of immigrant Iranian women.

Keywords: breast cancer screening, social support, immigrant women
Volume 3 Issue 4 - 2015

\author{
Mehra Shirazi \\ Oregon State University, USA
}

\begin{abstract}
Correspondence: Mehra Shirazi, Assistant Professor, Women, Gender and Sexuality Studies, 264 Waldo Hall, Oregon State University, Corvallis, OR, Tel 5418290029, Email mehra.shirazi@oregonstate.edu
\end{abstract}

Received: October 23, 2015 | Published: November 20, 2015

\section{Introduction}

Breast cancer is the second most common newly diagnosed cancer and second leading cause of cancer death among women in the US. ${ }^{1}$ In 2013, an estimated 232,340 new cases of invasive breast cancer were expected to be diagnosed among US women, as well as an estimated 64,640 additional cases of in situ breast cancer and approximately 39,620 US women were expected to die from breast cancer. Only lung cancer accounts for more cancer deaths in women.Breast cancer incidence rates are highest in non-Hispanic white women, followed by African American women and are lowest among Asian/Pacific Islander women. In contrast, breast cancer death rates are highest for African American women, followed by non-Hispanic white women. Breast cancer death rates are lowest for Asian/Pacific Islander women. Breast cancer incidence and death rates also vary by state. ${ }^{1}$

It has been well established that there are strong links between social support and positive health outcomes. Many studies have reported the positive influence of social support on women's psychological well being and coping abilities through every stage of breast cancer. ${ }^{2}$

However, very few studies have specifically explored the influence of social support on breast cancer screening. McCance and collegues (1996) examined the importance of influence of other people in getting women to obtain breast cancer screening. Results revealed that the influence of others was highly significant to the practice of breast self-examination and less so for mammography and clinical breast examination. A study by ${ }^{3}$ investigated the relationship between social support and the frequency and accuracy of BSE practice. Social support was found to be significantly related to the frequency of BSE, but not to the accuracy of BSE. The results also indicated that older women had lower social support scores compared with younger women. ${ }^{3}$ Another study examined the influence of social support and adherence to recommended breast cancer screening guidelines among a multicultural community. ${ }^{2}$ The study participants from three racial or ethnic groups (Latina, Caucasian, and African American) who were not breast cancer survivors. The results showed higher levels of social support were related to higher income and higher education. Lower levels of social support were associated with being Latina, completing the survey in Spanish, and being born abroad. Women who did not adhere to screening guidelines (for BSE or CBE) reported less social support. ${ }^{2}$ Patriarchal marital beliefs and gender roles also dictate the support women have for early detection behavior. Studies show that women concealed their participation in breast cancer screening from their male partners or did not seek help for symptoms because their husband did not want a male doctor to perform their breast examination. ${ }^{4}$

Numerous studies have documented the role of physicians in influencing their patients' participation in screening. ${ }^{5}$ Studies in a variety of populations demonstrate that physician recommendation is one of the most important predictors of breast cancer screening behaviors. A study by Slenker et al. ${ }^{6}$ showed that $89.6 \%$ of the women who had been asked by a doctor to get a mammogram had complied with the request, and only $10.4 \%$ of the women who had not been asked to get a mammogram had done so. 
A study of largely latinas found that physician recommendation and discussion with a doctor or nurse was associated with ever having a mammogram. ${ }^{7}$ Studies that included minority women documented a dramatic improvement in the proportion of these women who obtained a mammogram after their doctors recommended this screening procedure. ${ }^{8}$ Strong patient-provider relationships, with high levels of trust, have also led to better health through adherence to recommended preventive services for low income African-American women. ${ }^{9}$ Physician communication problems may exist due to religious, cultural and linguistic differences between women and their physicians. Furthermore, research also indicates that physicians are less likely to share information with individuals whom they perceive to be different from themselves in terms of social class, ethnicity, gender, and age. Considering that physician recommendation is one of the most determinants of mammography, the lack of communication between physician and the patient is especially detrimental to breast cancer screening rate in this group. Studies also indicate that along with health-professional interventions and SES, and legal status of immigrant women also determine their level of cancer screening. ${ }^{10,11}$ For example in regards to mammography women with no usual source of health care, no health insurance and women who had migrated to the United States within the last 10 years were least likely to have had a mammogram within the last 2 years. ${ }^{12}$

In general the literature suggests a direct link between an individual's interaction with social networks and the use of breast cancer screening. Recognizing the importance of early detection in saving lives and increasing treatment options, understanding the underlying factors that influence women's breast cancer screening practices is essential.

\section{Conceptual framework}

The Theory of Planned Behavior (TPB $]^{13}$ provided the conceptual frame for the present study. TPB states that the most proximate and strongest predictor of whether an individual will perform a certain behavior is their intention to perform that behavior. The theory focuses on the determinants of behavioral intention and asserts that behavioral intention is informed by: one's overall attitude toward the action, including expectations of the outcomes associated with the action; one's belief that people important to them believe that should or should not perform the action (known as subjective norm) and beliefs about those norms; and one's perceived control, one's perceived ease or difficulty, regarding performance of the action.

\section{Methods}

The study design was a cross-sectional survey. The participants in this study consisted of self-identified first generation immigrant Iranian women who were born and/or lived in Iran before they migrated to the United States $(\mathrm{N}=341)$. A snow -ball method of recruitment was used. Study participants included: a) Iranian born women between the ages of 30-80 years who lived in California, b) Iranian women able to read and speak English and /or Farsi.

\section{Instrument}

Social support on breast cancer screening was assessed using three subscales measuring the perceived support from 1) husband/partner; 2) family/relatives; and 3) friends as it relates to compliance with breast cancer screening guidelines. Health professional recommendation was assessed by asking; 1) if a health professional (for example doctor, nurse) has taught them how to perform breast self-examination; 2) if a doctor has recommended that they get a mammogram. History of Breast problems was assessed by asking whether the woman has ever experienced; 1) unusual pain, swelling or a lump; 2) an abnormal mammogram that resulted in further testing; 3) both or ; 4) none. Family history of breast cancer was assessed by asking the woman if anyone close to her had ever been diagnosed as having breast cancer (yes/no). Personal history of breast cancer was assessed by asking the woman if she had ever been diagnosed with breast cancer (yes/no).

The demographic questionnaire gathered information about age, education level, income, marital status, length of stay in the United States, regular physician, provider's gender and language and health insurance coverage.

Previously developed mammography, CBE, BSE behavior indices developed by the ACS guidelines was adapted to measure compliance/ frequency of early detection behaviors. Breast cancer screening was measured by obtaining information on frequency/compliance with BSE, CBE, and mammography screening. Women were asked whether they ever had that procedure and were coded accordingly (yes/no/Not Applicable). The women were also asked if they had been recently screened. Regarding mammography in addition to compliance/frequency items were developed to assess purpose and total number of mammograms.

Internal consistency reliability assessment using cronbach's alpha was conducted for the pre-test survey. Item analysis of each subscale was performed. The social support scale had three sub-scales to assess support from husband/partner, families and friends for BSE, CBE and mammogram. The internal consistency reliabilities for each sub-scale ranged from .82 to .96 and the Cronbach's alpha for the combination of the three sub-scales was .90 .

\section{Procedure}

Participants were recruited through community meetings, special events, and informal gatherings .Several special events such as the Iranian Women's day, Mother's day and religious celebrations were held during the data collection period where particpants were and recruited.By surveying a variety of groups and multiple settings the diversity of the women participants in terms of age, education, and income was expanded. Upon recruitment each participant received a questionnaire package in the language of their choice (English or Farsi) containing a cover letter with information pertaining to the study, an informed consent document, and the questionnaire and an informational booklet on breast cancer screening. Particpants completed the questionnaire on site.

\section{Statistical analysis}

Statistical analysis was performed using SPSS version 23 software. Descriptive statistics was used to understand women's breast cancer screening practices, demographic characteristics, socioeconomic status, and social support for breast cancer screening. Logistic regression was used to identify predictors of women's breast cancer screening. First bivariate analysis was performed to determine which independent variables would distinguish women who ever had/ never had breast cancer screening and those who had regular breast cancer screening. The logistic regression results appear as odds ratios (ORs) and 95\% confidence intervals. Backward stepwise multivariate logistic regression using the method of likelihood estimation was conducted to identify the most important predictors after adjusting for other variables ( $\mathrm{P}>.05$ for removal from model). 


\section{Results}

\section{Socio-demographic characteristics}

Table 1 summarizes the socio-demographic characteristics. Participants in this study consisted of Iranian immigrant women ages 30 and older living in California. The mean age of study participants was 44 years $(\mathrm{SD}=2.01)$ with a range in age of 30 to 75 years. With $27.6 \%$ of the women in the $40-45$ age category. About $31.1 \%$ of the women were under 40 and $24.1 \%$ were 50 years of age or older. All participants were immigrants, with a mean length of residence in the United States of 16 years. Over 68 percent $(68.3 \%)$ of the respondents were married. Many of the respondents had completed college education $(65.7 \%)$. Sixty four percent of the women were currently employed and $13.8 \%$ were full time home- makers. The Median income was $\$ 69,000$, but $8.8 \%$ also reported earning less than $\$ 10,000$

Table I Demographic characteristics

\begin{tabular}{|c|c|c|}
\hline $\mathbf{N}=341$ & $\mathbf{n}$ & $\%$ of sample \\
\hline \multicolumn{3}{|l|}{ Age (years) } \\
\hline $30-35$ & 71 & 20.8 \\
\hline $36-39$ & 35 & 10.3 \\
\hline $40-45$ & 95 & 27.9 \\
\hline $46-49$ & 58 & 17 \\
\hline $50-55$ & 30 & 8.8 \\
\hline $56+$ & 52 & 15.3 \\
\hline \multicolumn{3}{|l|}{ Marital status } \\
\hline Married & 233 & 68.3 \\
\hline Widowed & 16 & 4.7 \\
\hline Divorced/Separated & 50 & 14.7 \\
\hline Never Married & 42 & 12.3 \\
\hline \multicolumn{3}{|l|}{ Education level } \\
\hline Less than High School & 12 & 3.6 \\
\hline Completed High School & 37 & 10.9 \\
\hline Some College & 68 & 19.9 \\
\hline College and Above & 224 & 65.7 \\
\hline \multicolumn{3}{|l|}{ Employment status } \\
\hline Currently Unemployed & 61 & 17.9 \\
\hline Currently Employed & 219 & 64.2 \\
\hline Homemaker & 47 & 13.8 \\
\hline Retired & 14 & 4.1 \\
\hline \multicolumn{3}{|c|}{ Yearly household income } \\
\hline LESS THAN $\$ 10,000$ & 30 & 8.8 \\
\hline \$10,000 TO \$19,999 & 12 & 3.5 \\
\hline$\$ 20,000$ TO \$29,999 & 34 & 10 \\
\hline$\$ 30,000$ TO \$ 39,999 & 37 & 10.9 \\
\hline$\$ 40,000$ TO \$ 49,999 & 47 & 13.8 \\
\hline$\$ 50,000$ TO $\$ 74,999$ & 38 & II.I \\
\hline$\$ 75,000$ TO \$ 99,999 & 47 & 13.8 \\
\hline$\$ 100,000$ and Over & 64 & 18.8 \\
\hline \multicolumn{3}{|l|}{ Health insurance } \\
\hline Yes & 295 & 86.5 \\
\hline No & 46 & 13.5 \\
\hline
\end{tabular}

Table Continued...

\begin{tabular}{lcc}
\hline N= 34I & \multicolumn{2}{c}{ \% of sample } \\
\hline Regular primary health care provider \\
Yes & 293 & 85.9 \\
No & 48 & 14.1 \\
Gender of primary health care provider \\
Male & 164 & 48.1 \\
Female & 158 & 46.3 \\
NA & 19 & 5.6 \\
Prior experience of breast abnormality \\
Unusual breast condition & 40 & 11.7 \\
Abnormal mammogram & 21 & 6.2 \\
Both & 75 & 22 \\
No & 205 & 60.1 \\
History of breast cancer & & \\
Yes & 25 & 7.3 \\
No & 316 & 92.7 \\
Family/friend with breast cancer & \\
Yes & 128 & 37.5 \\
No & 213 & 62.5 \\
\hline
\end{tabular}

The majority of the women were insured (86.5\%) and $85.9 \%$ reported that they had a regular primary health care provider. Among the participants $11.7 \%$ had a prior experience with unusual breast symptoms, and $6.2 \%$ had received an abnormal mammogram. Twenty two percent reported experiencing both. More than half of the women (60.1\%) had no prior experience with any unusual symptoms and/or an abnormal mammogram. Approximately $7.3 \%$ of the women had been diagnosed with breast cancer. Among the respondents 30.7\% reported knowing a relative or a close friend who had been diagnosed with breast cancer.

\section{Social support}

Results of the social support scale are shown in Table 2. Women had strong to moderate support from their husbands/partners, family members and friends to practice breast cancer screening practices. More than $50 \%$ of the women reported strong support from family members to engage in mammography. BSE was the least discussed among all three social support scales followed by CBE. More than nineteen percent reported never discussing BSE with their husband / partner, and more than $24 \%$ never discussed BSE with either friends or family members. Twelve percent of the women never discussed CBE with husbands/partners, $18.8 \%$ never discussed CBE with family members and $20.8 \%$ never discussed CBE with friends.

\section{Breast cancer screening profile}

A total of $86.2 \%$ of the women had practiced BSE at least once, Only $38.1 \%$ participants practiced BSE once a month and $18.5 \%$ reported not practice at all. The comparatively lower BSE rates are in contrast with the higher annual CBE and mammography rates. The majority (93\%) of the women indicated having had at least one CBE. Seventy three percent (73\%) of the participants ages 40 and up reported having had a CBE every year. Among women below the age of $40,65.4 \%$ reported having a CBE every year and $10.3 \%$ having a CBE every two to three years. In this study nearly all participants had heard of mammography (94.1\%), among women ages 40 and up, $7.7 \%$ of the had never had a mammogram. For women ages 40 and up $55.5 \%$ had a mammogram less than a year ago and $25.6 \%$ of the women had a mammogram one year ago. Therefore, $81.1 \%$ 
of the women age 40 and up reported having a mammogram within the last year, and $9.4 \%$ of the women reported having undergone mammography more than two years ago. Routine screening was the reason for obtaining a recent mammogram for $59.5 \%$ of the women.

\section{Multivariate analysis for breast cancer screening practices}

Table 3 summarizes the results of the multiple logistic regression analysis including the odds ratios and their corresponding confidence intervals for breast cancer screening practice. The multivariate analysis indicated women with an AA college degree or higher and those who were taught by a physician how to perform breast selfexamination $(\mathrm{OR}=19.97, \mathrm{P}=.000)$ were more likely to have ever had a BSE. Women who received support from their friends to perform BSE were 2.13 times more likely to have ever had a BSE.
Those who lived in the United States for more than 10 years $(\mathrm{OR}=6.76, \mathrm{P}=.000)$ with prior experience of breast abnormality $(\mathrm{OR}=7.1, \mathrm{P}<.003)$ were more likely to have ever had a CBE. Having a regular source of health care was not a very significant factor in the final model $(\mathrm{OR}=2.45, \mathrm{P}<.084)$.

Women who received support from their husbands/partners were 3.5 times more likely to have ever had a CBE. Women who lived in the United States for more than 10 years $(\mathrm{OR}=6.97, \mathrm{P}<.007)$, were recommended by their physician to get a mammogram $(\mathrm{OR}=22.6$, $\mathrm{P}=.000)$, communicated with their physician in English $(\mathrm{OR}=5.11$, $\mathrm{P}<.015)$ and had prior experience with breast abnormalities $(\mathrm{OR}=$ 22.6, $\mathrm{P}<.009)$ and received support from their husband $\mathrm{s} /$ partners were more likely to have ever had a mammogram $\mathrm{OR}=2.51, \mathrm{p}<.004$ ).

Table 2 Perceived social support for breast cancer screening $(\mathrm{N}=34 \mathrm{I})$

\begin{tabular}{llllll}
\hline \multirow{2}{*}{ Source of support } & \multicolumn{6}{l}{ Level of support (\%) } & & \\
\cline { 2 - 6 } & High & Moderate & Low & Never discuss & Not applicable \\
\hline Husband/Partner & & & & & \\
BSE & 35.2 & 15 & 5 & 19.6 & 25.2 \\
CBE & 38.4 & 19.1 & 5.3 & 12.6 & 24.6 \\
Mammogram & 39.6 & 19.1 & 5.9 & 10.9 & 24.6 \\
Family & & & & & \\
BSE & 44 & 18.5 & 6.5 & 25.8 & 5.3 \\
CBE & 47.8 & 23.5 & 5 & 18.8 & 5 \\
Mammogram & 50.4 & 22 & 5.9 & 17 & 4.7 \\
Friends & & & & & \\
BSE & 38.4 & 24.9 & 7.6 & 24.6 & 4.4 \\
CBE & 41.3 & 26.1 & 8.2 & 20.8 & 3.5 \\
Mammogram & 44.6 & 26.4 & 7.9 & 17.6 & 3.5 \\
\hline
\end{tabular}

Table 3 Multiple logistic regression model of association between significant variables and BSE, CBE and mammography practice

\begin{tabular}{|c|c|c|c|c|c|c|c|c|c|}
\hline \multirow{2}{*}{ Variables } & \multicolumn{3}{|l|}{ BSE } & \multicolumn{3}{|l|}{ CBE } & \multicolumn{3}{|c|}{ Mammography (I) } \\
\hline & OR & $\mathbf{P}$ & Cl & OR & $\mathbf{P}$ & $\mathrm{Cl}$ & OR & $\mathbf{P}$ & Cl \\
\hline Education & 2.03 & 0.07 & $.958-4.32$ & ns & ns & ns & ns & ns & ns \\
\hline Years in US & ns & ns & ns & 6.76 & 0 & $2.63-17.42$ & 6.97 & 0.007 & $1.69-28.6$ \\
\hline Regular Physician & ns & ns & ns & 2.45 & 0.084 & $.888-6.78$ & ns & ns & ns \\
\hline Physician Recommended (2) & & & & & & & 22.6 & 0 & $5.16-98.75$ \\
\hline Physician Taught breast & 19.97 & 0 & $9.39-42.47$ & & & & & & \\
\hline Physician Language & ns & ns & ns & ns & ns & ns & 5.11 & 0.015 & $1.37-19.02$ \\
\hline Experience of breast Abnormality & ns & ns & ns & 7.1 & 0.003 & $1.92-26.12$ & 22.6 & 0.009 & $2.19-232.1$ \\
\hline \multicolumn{10}{|l|}{ Social Support } \\
\hline Husband/Partner & & & & 3.52 & 0.012 & I.32-9.39 & 2.51 & 0.004 & $.170-1.44$ \\
\hline Family/Relatives Friends & 2.13 & 0.05 & $\mathrm{I} .0 \mathrm{I}-4.49$ & & & & & & \\
\hline
\end{tabular}

I-Mammography for women 40 and up

2- Has a physician ever advised you to get a mammogram?

3-Has a doctor or health care provider taught you how to perform breast self-examination?

Ns, Not significant

\section{Discussion}

This study looked at the influence of social support and physician recommendation on breast cancer screening practices of immigrant Iranian women in the United States.

In non- Western cultures such as Iran, the family ,group or community often assumes major responsibility for its members' well- being.${ }^{14} \mathrm{~A}$ study of immigrant Iranian women's adaptation to life in the United states points out that a key factor influencing the quality of life and well -being of all the women in the study was their relationship with their families. Relationships with spouses, children, grandchildren, and friends were a major source of life satisfaction. The study concludes that the nature of ones social and emotional support greatly influences adjustment to the new cultural environment. ${ }^{14}$ In this study 
women had strong to moderate support from their husbands/partners, family members and friends to practice breast cancer screening More than $50 \%$ of the women reported strong support from family members to engage in mammography. A study by Wagle et al. ${ }^{3}$ investigated the relationship between social support and the frequency and BSE practice. Social support was found to be significantly related to the frequency of BSE. The results of this study also showed social support from friends was a significant predictor of ever having had a BSE and husband/partner support was a significant predictor of ever having had a CBE and a mamogram. BSE was the least discussed among all three social support scales followed by CBE. Among the participants only $38.1 \%$ practiced BSE once a month and $18.5 \%$ reported not practice at all. More than nineteen percent reported never discussing BSE with their husband /partner, and more than $24 \%$ never discussed BSE with either friends or family members. One explanation for low rates of BSE discussion could be cultural barriers in regards to conversations about intimate body parts which have been shown to be a barrier to screening for Asian and Latina and Muslim women. In case of Muslim immigrant women, Rashidi et al., ${ }^{15}$ argues that the unique complexities in the socio-cultural backgrounds of these women could also hinder access to healthcare services. Among the socio-cultural barriers are patient-physician communication difficulties and beliefs about cancer and cancer prevention. Health care professionals may also have stereoptypical ideas about Muslim women as being powerless, uneducated and subservient. ${ }^{16}$ Several qualitative studies suggest that modesty concerns and the preference for female providers among Muslim women pose barriers to their obtaining mammograms. ${ }^{15,17-19}$ These studies also of breast cancer suggest that religious beliefs and cultural values of Muslim women have significant impact on whether they are enabled and supported to participate in screening exams.

Numerous studies have documented the role of physicians in influencing their patients' participation in screening. ${ }^{5,17}$ and many studies have linked women's SES to lower screening behavior For example, physicians perceptions about the cost of mammography, women's inability to pay combined with Physician communication and racial prejuidices due to race/ethnicity ,religious, cultural and linguistic differences between women and their physicians may reduce the likelihood of recommendation. ${ }^{20-23}$ A study by O'Malley et al. ${ }^{24}$ investigated the association between physician recommendation and women's race/ethnicity, socioeconomic status (SES), found physician recommendation was was lower among racialy marginalized women who were vulnerable--older, with lower income, and lower educational attainment. Another study have shown a significant association between perceived racial or ethnic-based medical discrimination and cancer screening behaviors ${ }^{25}$ Of particular concern when studying immigrant populations, is failure to consider the specific nature of the host or "mainstream" society. In its health research application, the existence of a particular "mainstream" culture to which people are adapting is implicitly speculated. This presumption seems misguided, given the complex nature of Western society. A more appropriate representation might be one that assumes an intricate pattern, wherein a variety of cultures contribute to the overall fabric of the larger society. ${ }^{26}$ In order to better understand life transitions of these women, Anderson argues, that the direction of future research "should make space to understand cultural meanings not as neutral scripts for people's lives tied to their ethnic roots, but as dynamic socially, socially constructed, produced within historical, gendered, raced, and political contexts" and the need to explore the interactions between racialization, gender and SES (2000).

Certain study limitations when interpreting the results of this study needs to be considered. The most important was the use of a convenience sample of immigrant Iranian women. Therefore findings may not be generalizable to the broader population of immigrant Iranian women in the US.

Second, the data came from self-reports and were subject to recall and desirability response bias. Because of the tendency of the subjects to answer questions the way they think is preferred frequency of breast cancer screening practices may have been overestimated. Despite these limitations by using the Theory of Planned Behavior (TPB), the findings from this study adds to the body of literature suggesting that breast cancer screening programs will be more effective if they include enabling, and social support factors associated with breast cancer screening.

\section{Acknowledgments}

None.

\section{Conflicts of interest}

The authors declare there is no conflict of interests.

\section{Funding}

None.

\section{References}

1. American Cancer Society. Cancer facts \& figures 2014. Atlanta, USA:American Cancer Society; 2014

2. Katapodi MC, Facione NC, Miaskowski C, et al. The influence of social support on breast cancerscreening in a multicultural community sample. OncologyNursing Forum. 2002;29(5):845-852.

3. Wagle A, Komorita NI, Lu ZJ. Social support and breast selfexamination. Cancer Nurs. 1997;20(1):42-48.

4. Salazar MK. Hispanic women's beliefs about breast cancer and mammography. Cancer Nursing. 1996;19(6):437-446.

5. Lerman C, Rimer B, Trock B, et al. Factors associated with repeat adherence to breast cancer screening. Preventive Medicine. 1990;19(3):279-290.

6. Slenker SE, Grant MC. Attitudes, beliefs, and knowledge about mammography among women forty years of age. J Cancer Educ. 1989;4(1):61-65.

7. Zapka JG, Stoddard A, Barth R, et al. Breastcancerscreening utilization by Latina community health center clients. Health Edu Res. 1989;4(4):461-468.

8. Zapka JG, Harris DR, Hosmer D, et al. Effects of community health center intervention on breastcancerscreeningHispanic American women. Health Serv Res. 1993;28:221-235.

9. O’Malley MS, Sheppard VB, Schawartz M, et al. The role of trust in use of preventive services among low-income African-American women. Prev med. 2004;38(6):777-785.

10. Harlan LC, Bernstein AB, Kessler LG. Cervical cancer screening: Who is not screened and why? Am J Public Health. 1991;81(7):885-890.

11. Saint-Germain MA, Bassford TL, Montano G. Surveys and focus groups in health research with older Hispanic women. Qualitative Health Research. 1993;3:341367.

12. Swan J, Breen N, Coates RJ, et al. Progress in cancer screening practices in the United States:results from the 2000 National Health Interview Survey. Cancer. 2003;97(6):1528-1540.

13. Ajzen I. Behavioral Interventions:Design and Evaluation Guided by the Theory of Planned Behavior. In: Mark MM, et al. editors. Social Psychology and Evaluation; 2011:74-101. 
14. McConatha TF, Stoller P, Oboudiat F. Reflections of older Irananian women adapting to life in the United States. Journal of Aging Studies. 2001;15(4):369-381.

15. Rashidi A, Rajaram SS. Middle Eastern Islamic Women and Breast Self-Examination. Cancer Nur. 2000;23(1):64-70.

16. Meleis A, Hatter-Pollard M. Arab Middle Eastern American women. Stereo typed invisible but powerful. In:Adams DL (Ed.), Health Issues for Womenof Color:A cultural diversity perspective. Sage Publications; 1995:133-163.

17. Shirazi M, Bloom J, Shirazi A, et al. Afghan immigrant women's knowledge and behaviors around breast cancer screening. Journal of Psycho-Oncology. 2013;22(8):1679-1917.

18. Matin M, LeBaron S. Attitudes toward cervical cancer screening among Muslim women:a pilot study. Women Health. 2004;39(3):63-77.

19. Underwood S, Shaikha L. Veiled yet vulnerable. Breast cancer screening and the Muslim way of life. Cancer Practice. 1999;7(6):285-290.

20. Jiwani Y. Intersecting Inequalities:Immigrant Women of Colour, Violence and Health Care. Vancouver:Feminist Research Education Development and Action (FREDA) Centre, Canada, USA; 2001.
21. Jiwani Y. Gendered Racism, Sexist Violence, and the Health Care System. In Discourses of Denial: Mediations of Race, Gender, and Violence. Vancouver: UBC Press; 2006.

22. Burack RC, Liang J. The acceptance and completion of mammography in older black women. American Journal of Public Health. 1989;79(6):721-726.

23. Dolan NC, Reifler DR, McDermott MM, et al. Adherence to screening mammography recommendations in university general medicine clinic. J Gen Intern Med. 1995;10(6):299-306.

24. O’Malley MS, Earp JA, Hawley ST, et al. The association of race/ ethnicity, socioeconomic status, and physician recommendation for mammography: Who gets the message about breast cancer screening? Am J Public Health. 2001;91(1):49-46.

25. Lavera M, Ahn D, Winkleby M. Perceived Medical Discrimination and Cancer Screening Behaviors of Racial and Ethnic Minority Adults. Cancer Epidemiol Biomarkers Prev. 2008;17(8):1937-1944.

26. Berry JW. Ethnic Identities in Plural Societies. In: Bernal, et al. editors. Ethnic identity: Formation and transmission among hispanics and other minorities, USA: Albany State University of New York Press; 1993:271-296. 